\title{
Behaviour and Seismic Design of Stiffeners for Steel Bridge Tower Legs and Piers
}

\author{
Xin Qian, Abolhassan Astaneh-Asl \\ University of California at Berkeley \\ Berkeley, California, USA \\ astaneh@berkeley.edu
}

\begin{abstract}
Thin-walled steel box colu mns have wide applications in piers of urban highway bridges, and in the towers of suspension and cable-stayed bridges. Currently, in practice, the stiffeners for tower legs and steel box pier columns are flat plates, all having the same cross sections and equally spaced from each other and from outside walls. With the constraint due to the adjacent walls, and with the stiffeners, especially the middle stiffeners, being not stiff and strong enough to form nodal lines due to yielding during cyclic loading, the middle portion of the stiffened plate tends to have the largest out-of-plane deformation. A new and more efficient concept for design of longitudinal stiffeners is proposed in this paper - to invest more stiffening material in the middle stiffeners instead of making all stiffeners to have the same cross section. In addition, based on the studies summarized here, we propose to use se ctions other than flat plates as stiffeners. We studied the effects of stiffeners cross sections and stiffener spacing on the local and overall buckling as well as the resulting stiffness and cyclic ductility of the steel box pier and steel tower legs. Our investigations showed that using stiffeners with an angle, plate or pipe welded to the traditional flat plate stiffener can improve the performance of the stiffened plate considerably - delay local buckling and increase cyclic ductility of the stiffened plate. Some of the new stiffener geometries we studied and recommended can very efficiently be used in seis mic retrofit of the steel box piers and tower legs of elevated freeways and major cable-supported suspension and cable-stayed bridge towers.
\end{abstract}

Keywords: Steel Structures, Bridge Engineering, Earthquake Engineering, Stiffened Steel Plates, Seismic Retrofit, Suspension Bridges, Seismic Design

\section{Introduction}

Thin-walled steel box columns have wide applications in piers of urban highway bridges, and in the towers of suspension and cable-stayed bridges, Fig. 1. The gravity load and lateral force imposed on these steel box columns and tower legs often translate into pure axial or combined axial and bending on the thin steel plate walls of the piers or towers. Like the stiffened deck plate in orthotropic deck system, the walls of such box columns are often stiffened steel plates. The primary role of the stiffeners is to prevent local buckling prior to overall buckling and to increase overall buckling strength. In seismic applications, an additional, yet equally important role of stiffeners is to increase ductility of the cross section under cyclic loading. During past earthquakes, especially during the 1995 Hyogoken-nanbu (Kobe, Japan) earthquake, steel box piers and tower legs of several major elevated freeways and long span bridges were severely damaged due to local buckling, Fig. 2.

This research was initially inspired by the pushover analysis of the main tower of the new Self-Anchored Suspension Bay Bridge [1], where buckling of the stiffened tower leg plates were observed and faster strength degradation was resulted - the tower should be more ductile in resisting lateral force if only shear link yielding is happening. 


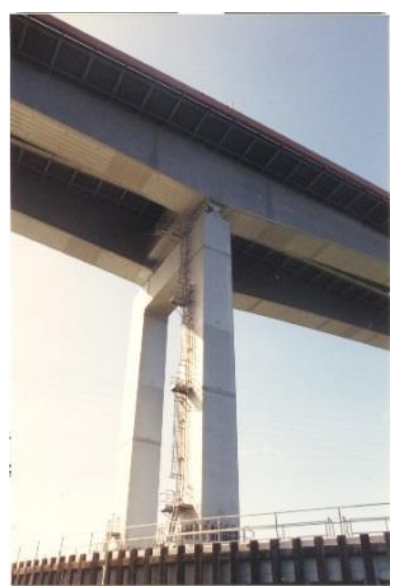

Fig. 1: Stiffened steel box bents of Hayward San Mateo Bridge in California (photo by Abolhassan Astaneh-Asl)
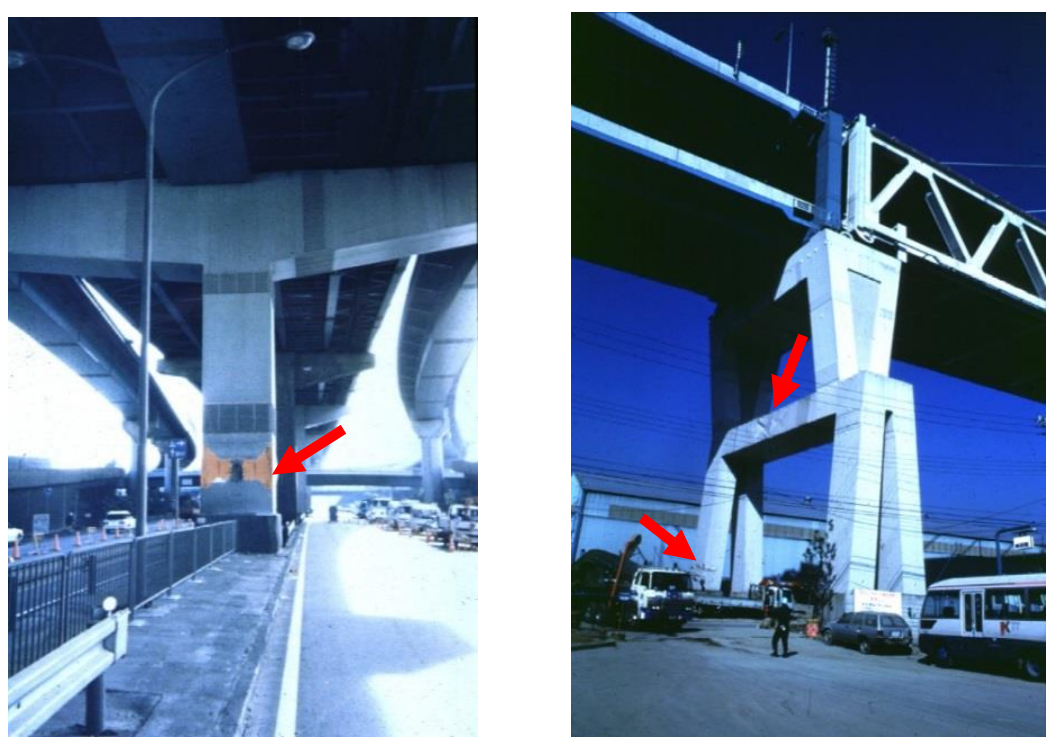

Fig. 2: Damage to stiffened box sections during the 1995 Hyogoken -nanbu (Kobe, Japan) earthquake (photos by Abolhassan Astaneh-Asl)

\section{Brief Literature Review}

The collapse behaviour of stiffened flanges received considerable attention in the 1970s and early 1980s. Some of the numerical and experimental studies formed the basis of the first generation of several codes of practice and design recommendations on this issue in the 1990s [2-6]. Since then, the details of the requirements were continuously updated. The design of longitudinally stiffened plates in several codes is based on the 'column' approach, which essentially convert the design of stiffened plates to the design of an equivalent column consisting of a single longitudinal stiffener with an associated width of the plate [7-10].

Besides the studies that focused mainly on the behaviour of isolated stiffened plates, Usami and his fellow researchers did extensive analytical and experimental investigations to understand the ductility behaviour of steel stiffened box columns, such as those shown in Fig. 4 under cyclic load [11-13]. They studied the relation of the stub-column ductility to various parameters such as the flange width-thickness ratio, axial force, stiffener's slenderness ratio, crosssectional property and aspect ratio of the column. Empirical ductility formulas were proposed. Only rectangular stiffeners were used in their studies. 
Yoo et al. presented an optimum design of longitudinal stiffeners for box-girder compression flanges in 2001[14]. Regression analysis was conducted to reduce the analysis results of several hundred hypothetical stiffened compression flange models to form a simplified design equation for longitudinal stiffener design - which is much less conservative than the AASHTO Bridge Design Specifications requirements at that time [15]. Their proposed equation of the stiffness requirement for the longitudinal stiffeners is essentially based on elastic buckling analysis and satisfactory collapse load for the stiffened plate.

\section{Objectives}

Note that most of the current practice and the above mentioned research involve the use of equally spaced stiffeners with the same dimension. With the constraint due to the adjacent walls, and with the stiffeners, especially middle stiffeners, being not stiff and strong enough to form nodal lines due to yielding or local buckling during cyclic loading, the middle portion of the stiffened plating tend to have the largest out-of-plane deformation. It is therefore rational to invest more stiffening material in the middle of the plating and less material towards the side walls instead of using equally spaced stiffeners throughout the entire width. Although one may achieve sufficient collapse load capacity by using the existing stiffener design philosophy, it may not be sufficient to control the rate at which the strength and ductility degrades under cyclic load applications.

The main objectives of this research project were to investigate the effects of (a) stronger middle stiffer (b) the use of stiffeners with cross sections other than currently used rectangular plate and (c) stiffener spacing on the local and overall buckling behaviour, stiffness and cyclic ductility of the steel box piers or steel tower legs.

\section{Nonlinear Finite Element Analyses}

In order to understand the behaviour of stiffened box columns under monotonic pushover and cyclic displacement history, we used the general-purpose analysis software ANSYS v15.0 [16] to analyse steel box columns with different stiffening schemes.

\subsection{Preliminary Study}

Preliminarily, we used a hypothetical boxed column $(1 \mathrm{~m}$ by $1 \mathrm{~m}$ by $5 \mathrm{~m})$ to study the effects of different arrangements of longitudinal stiffeners. We used four-node non-linear SHELL181 element to model both the box column and the longitudinal stiffeners. Simple bilinear kinematic hardening material model with $1 \%$ straining hardening ratio was used. The box columns were subjected to constant axial force ( $70 \%$ of yield capacity) and a monotonically increasing horizontal displacement. No horizontal diaphragm was provided along the height of the column. Although, not using horizontal diaphragm is rare in actual construction, the results are interesting and considered necessary to be presented in order to understand the effects of horizontal diaphragms in preventing buckling of stiffened plates.

Seven different cases, using various types and arrangements of stiffeners, as shown in Fig. 3(a), were analysed. They had three plate stiffeners on each wall (case 1), two plate stiffeners plus a middle T- stiffener (case 2), three Tstiffeners (case 3), two plate stiffeners plus a middle channel-stiffener (case 4), two T-stiffeners spaced at one-third of the column width (case 5), two T-stiffeners spaced at one-fourth of the column width (case 6) and two T-stiffeners spaced at one-fourth of the column width but with corner stiffeners (case 7). All plate and T-shape stiffeners are made of plate PL127mm by $13 \mathrm{~mm}$, and the channel section used is $101.6 \mathrm{~mm}$ by $63.5 \mathrm{~mm}$ by $12.7 \mathrm{~mm}$. Case 1 with rectangular plate stiffeners is considered as the reference, and other cases are designed to reduce the level of local buckling and improve the overall strength and ductility.

It was observed that by changing all three plate-stiffeners to T-stiffeners, the occurrence of local buckling could be delayed and stiffness and strength be improved. However, considering the amount of material and construction effort, it is not an ideal scheme for retrofit applications.

Adding a single horizontal plate in the middle did delay local buckling but without significantly increasing stiffness and ultimate strength. However, by changing the added horizontal plate to a channel section (case 4), a significant change of behaviour was observed - local buckling at the base of column is eliminated but overall buckling throughout the length of the column occurred (Fig.3(b) left), which results in a much higher pushover curve than all other cases. With this pronounced improvement, using relatively stronger middle stiffener than the two side stiffeners seem promising and provides a new and improved approach to design of longitudinal stiffeners. 


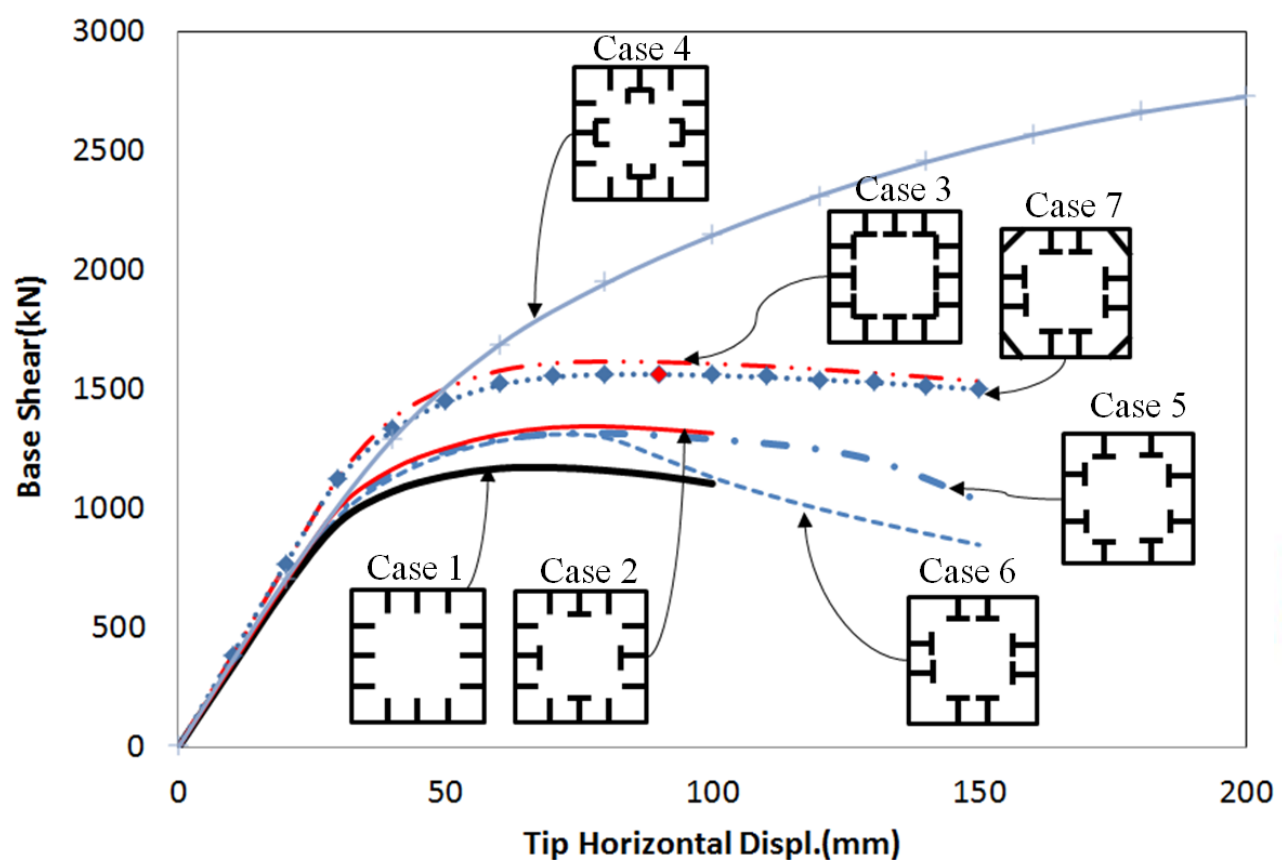

(a)
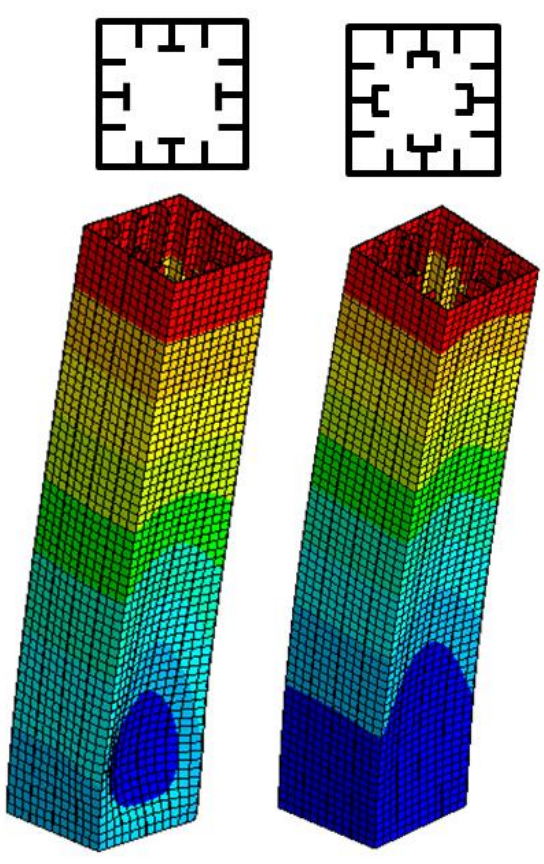

(b)

Fig. 3: (a) Pushover curves of preliminary stiffening schemes (b) Deformed shape of case 4 and case 2.

The analysis of cases 1 through 4 indicated that placing longitudinal stiffeners closer to the maximum deformed region (i.e., middle part of the plate), might be the direction to follow to control the post-buckling performance of the steel stiffened box columns. Therefore, case 5 and case 6 were designed. Case 5 with two T-stiffeners spaced at one-third of the panel width essentially has the same pushover curve as case 2. Case 6 with two T-stiffeners spaced at one-fourth of the panel width result in similar stiffness and yielding branch, but experiences faster strength degradation after initiation of local buckling due to lack of corner strengthening plate. By adding the corner plates in case 7, the curve increases to the level of case 3 with three T- stiffeners.

The most important result of this initial part of the study is that equal size stiffeners spaced at equal distance may not be the most effective way of controlling local buckling strength, post-buckling ductility and degradation of strength. Stronger central longitudinal stiffeners seem to be promising in producing effective retrofit schemes as well as resulting in efficient and economical new designs. The next section summarizes the main part of our investigation that was more extensive using finite element models validated by cyclic test results to conduct thorough parametric studies.

\subsection{The Prototype Typical Stiffened Steel Box Pier Studied \\ a. Introduction to the Chosen Specimen}

The chosen prototype typical stiffened steel box pier B14 is one of the box pier specimens tested by Usami et al [11]. It is a simple square box column with three plate stiffener on each side. Diaphragms plates are provided along the height of the column. The dimensions of the specimen as well as the material properties are shown in Fig. 4. The stiffeners and the box column had the same material properties. 


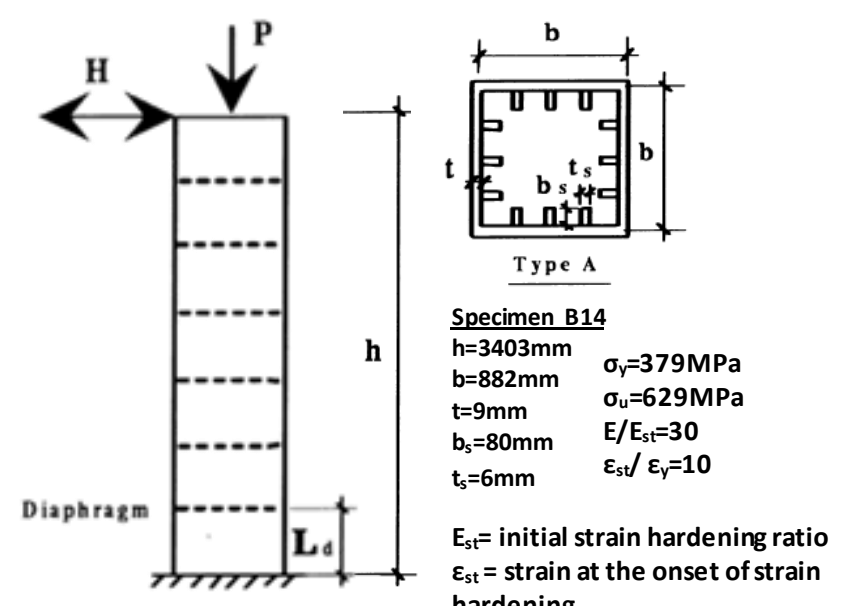

Fig. 4: Dimension and material properties of the chosen prototype specimen (adapted from [11])

\section{b. Modelling Material and Geome try}

We used SHELL181 elements to model all the components in the column system [16]. Based on the information available in ref [11], plasticity with multi-linear kinematic hardening material model was used to better capture the Bauchinger effect. In the original paper, kinematic hardening material model was found to over-estimate the post-buckling strength due to the inability to include the reduction of elastic range in the material level. To improve the material modeling, Ramberg-Osgood material model was applied to define the entire stress-strain relationship and a relatively large $n$ value was used, which causes the stress-strain curve to be closer to an elastic-perfectly plastic curve. As the experiment showed, the buckling and deformation are mainly concentrated at the bottom of the column; we used a fine mesh for the bottom segment of the column to capture the buckling of the stiffened plates (Fig.5) more accurately. Applied constant axial force and lateral displacement reversals follow the settings of the original paper. Residual stresses and initial imperfections were not included in the model due to lack of enough information. As can be seen from Fig.5, the adopted material model and mesh have in general lead to a reasonably good match to the test results; the initial stiffness and the first buckling strength are relatively well captured.
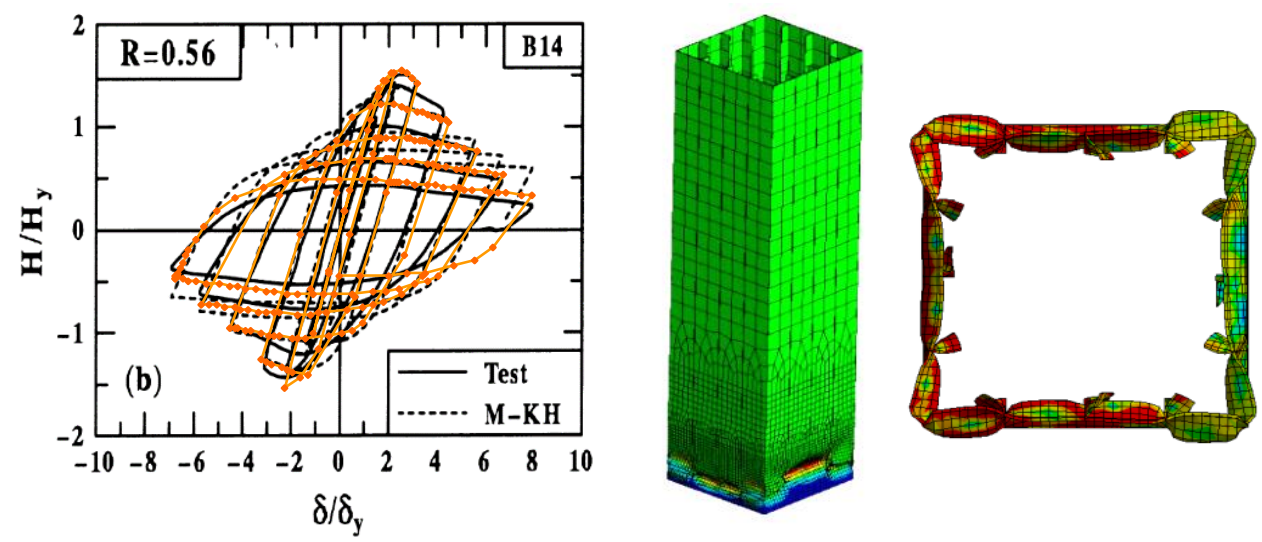

Fig. 5: Cyclic behavior of test specimen compared to analy sis results (left), buckled stiffened column, and cross section of buckled stiffened column for Usami et al [11] Specimen B14

\section{c. Comparison Study}

The stiffeners used in the Usami B14 specimen has a moment of inertia far greater than the design equation proposed by Yoo et al. [14] or the current AASHTO requirements [17]. It still, however, suffers from relatively fast strength degradation under cyclic loads. In order to control the strength degradation for important gravity carrying structures like bridge piers and towers, and to more rationally distribute the stiffening material, a number of new stiffening schemes based on the preliminary study are to be proposed and analysed in this section after validation of the finite element model with the test results. 
Table 1: Definition of models for comparison study.

\begin{tabular}{|c|c|c|c|c|c|c|c|c|}
\hline Case & Abbreviation & Shape & $\begin{array}{c}\text { Number of } \\
\text { stiffeners }\end{array}$ & $\begin{array}{c}\text { Stiffener } \\
\text { dimension(mm) }\end{array}$ & Material & $\mathrm{F}_{\mathrm{y}}(\mathrm{MPa})$ & $\begin{array}{c}\text { Fixed to } \\
\text { ground? }\end{array}$ & Ductility \\
\hline U & original & & & & & 379 & & 3.93 \\
\hline L1 & 3Ls-f Gr50 & Angle & 3 & $92.5 \times 9$ & Gr.50 & 379 & Yes & 5.13 \\
\hline L2 & 1Ls-f Gr50 & Angle & 1 & $92.5 \times 9$ & Gr.50 & 379 & Yes & 4.81 \\
\hline P1 & 3Ps-f Gr50 & Pipe & 3 & $96.5 \times 5.2$ & Gr.50 & 379 & Yes & 7.38 \\
\hline P2 & 1Ps-f Gr50 & Pipe & 1 & $96.5 \times 5.2$ & Gr.50 & 379 & Yes & 5.13 \\
\hline PL1 & 3PL-f Gr50 & Plate & 3 & $127 \times 12.7$ & Gr.50 & 379 & Yes & 5.29 \\
\hline PL2 & 1PL-f Gr50 & Plate & 1 & $127 \times 12.7$ & Gr.50 & 379 & Yes & 4.89 \\
\hline
\end{tabular}

A series of models were analyzed to explore the effects of shape, number and thickness of longitudinal stiffeners, fixity to the ground and material on the overall behavior of the column. This paper will mainly focus on the effects of the first two aspects. The analysis matrix is shown in Table 1. Three different shapes of added stiffeners were chosen, including plate, angle and pipe sections. In addition to the plate option, which is common, the stiffener T-shaped, angle and pipe sections were selected because of the additional bending and torsional stiffness that can be brought in by these cross-sectional shapes. All sections were selected to have similar material and construction cost by using similar crosssectional area and two weld lines. The angle sections are to be connected to the original plate stiffeners at the corner as shown in Fig.7.

\section{Results}

For all the cases, the ductility shown in Table 1 is defined to be the ratio of lateral displacement when the reaction force drops to $80 \%$ of the maximum strength over the displacement at yield. It can be seen from Table 1 is that all the proposed schemes with additional stiffening material, the resulting ductility gains at least $20 \%$ increase. Among the three different proposed shapes, pipe section always leads to the largest improvement in ductility, regardless of the number of additional sections used.
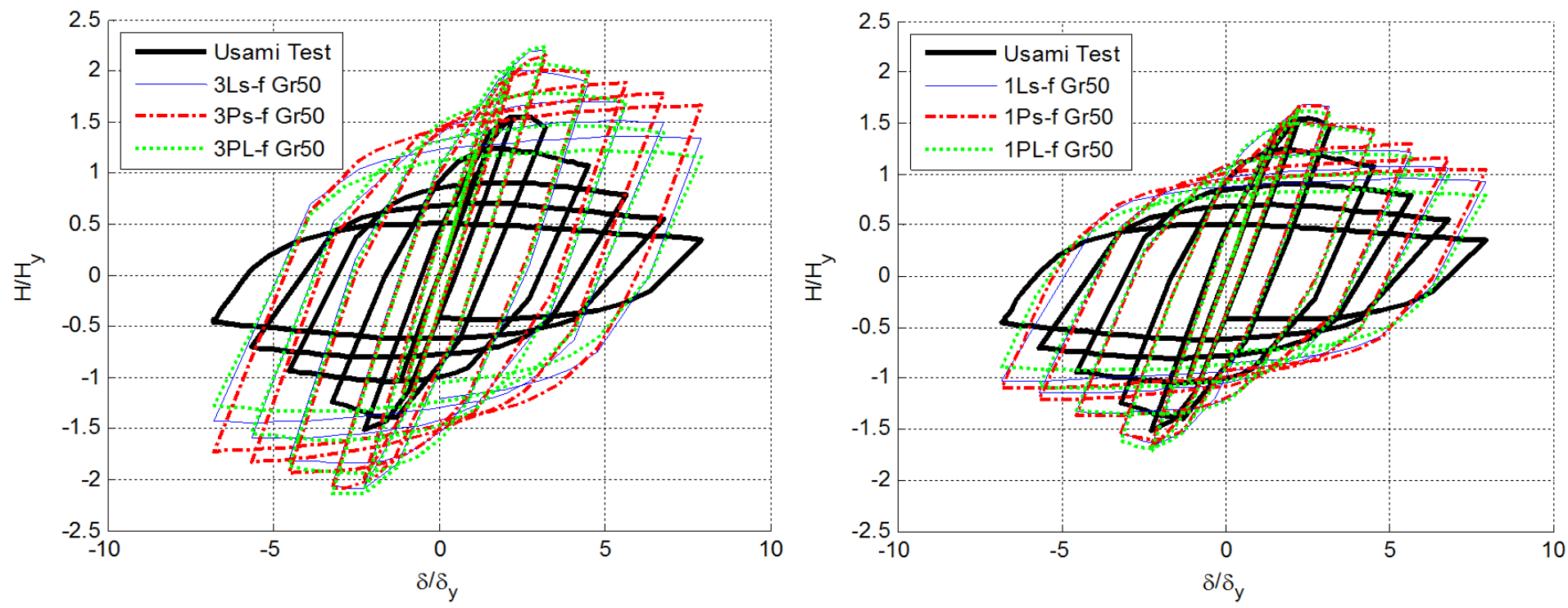

Fig. 6: Comparison of hysteresis loops of different stiffening schemes. 
Fig.6 also shows that pipe options, both 3-pipe and 1-pipe cases, have similar buckling load as the other two shapes but much slower degradation and thus fatter hysteresis loops. While the plate cases, though the stiffness and initial buckling load increased because of the contribution from the additional plates, they cannot maintain the strength under larger load reversals very well. This is probably due to the fact that the stiffness of single plate is smaller than that of an angle or a pipe, and the added material does not change the buckling pattern of the column walls - the buckling of the column walls is still symmetric type instead of anti-symmetric type (Fig.5 \& 7). Angle section works reasonably well in changing the column wall buckling pattern into anti-symmetric type, but maybe because the angle sections themselves, as open sections, are more susceptible to torsional buckling, case L1 (3Ls-f Gr50) and L2 (1Ls-f Gr50) are slightly less ductile than their counterparts that use pipe sections.

In terms of the effect of the number of stiffeners, due to the amount of material used, stiffening all three original plate stiffeners of course will lead to higher stiffness and initial buckling load. However, this is at the expense of cost. On the other hand, note that case P2 (1Ps-f Gr50) achieved almost the same ductility as case L1 (3Ls-f Gr50) with one third of the material and construction cost.

With collapse load requirements satisfied following the current design practices, if we take one step further, appropriate stronger middle stiffeners shown in this study could be a promis ing and cost-effective approach for stiffening the box columns and ensure their ductility performance under repeated loading condition. This is especially crucial for major gravity load bearing structures like bridge piers and towers.
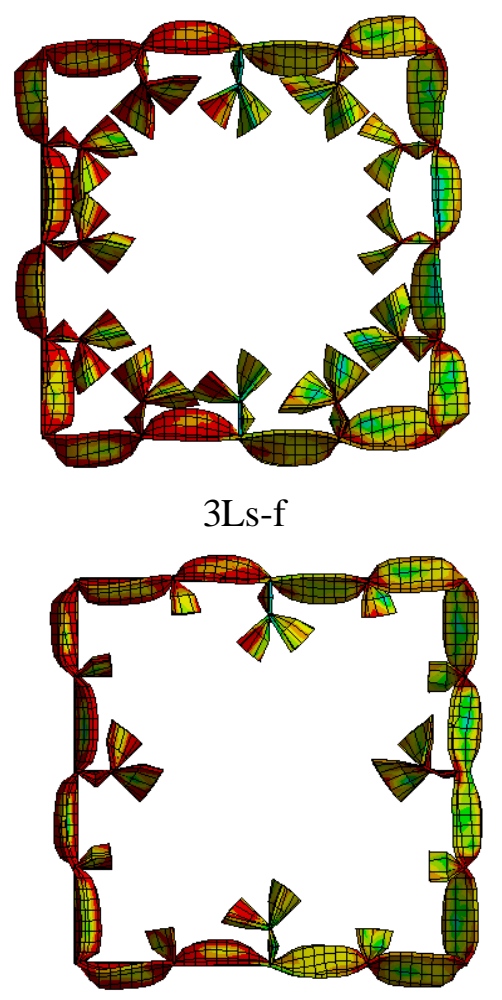

1Ls-f

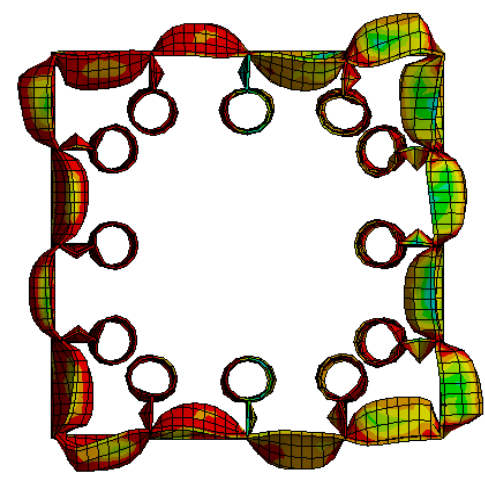

3Ps-f

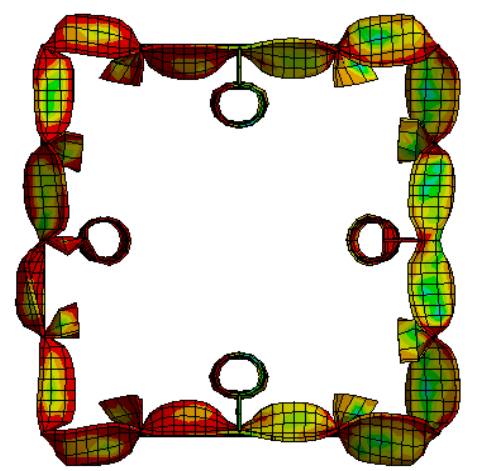

1Ps-f

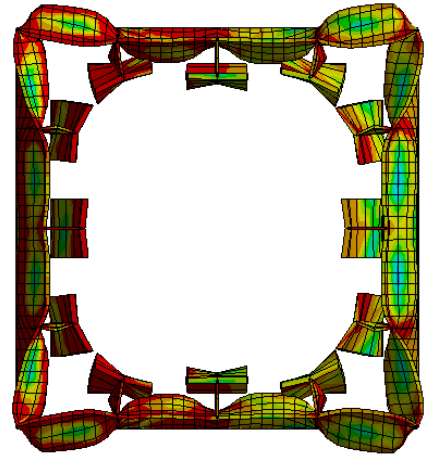

3PLs-f

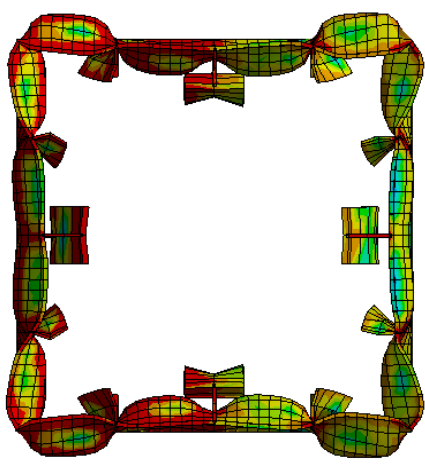

1PLs-f

Fig. 7: Comparis on of buckling patterns of different stiffening schemes .

\section{Conclusion}

Based on some preliminary studies, several modified stiffening schemes are proposed in this paper for thin-walled box columns. The proposed schemes include adding horizontal plates, angles and pipe sections to all three or only the middle existing plate stiffeners. The effects of the number and cross-section properties of the added sections were investigated. Sufficient strengthening only the middle stiffener was found to be effective in turning the symmetric 
buckling mode to anti-symmetric buckling mode, and can help to improve the buckling load and ductility behaviour. This indicates the potential of cost-effective design of new stiffened box column structures by more rational distribution of stiffening materials. Among the three proposed shapes, the pipe section works the best in terms of ductility improvement.

In conclusion, this paper provides a new perspective in seismic design of stiffeners for bridge tower legs and piers investing more stiffening material to the most flexible region, which is the middle of the plates, as well as using more efficient stiffener geometries such as pipes instead of just plate stiffeners.

\section{Acknowledgements}

This study was part of a larger project on "Investigation of Seismic Performance of the Self-Anchored Suspension Bay Bridge" [1] at the University of California Berkeley, USA, with Professor Abolhassan Astaneh-Asl, Ph.D., P.E., as the Principal Investigator. The authors would like to express their sincere appreciation for the tremendous technical support provided by Dr. Metin Ozen, President as well as Casey Heydari, and the analysts at Ozen Engineering Inc. (https://www.ozeninc.com/) on the use of the powerful ANSYS nonlinear structural analysis software featured in this project.

\section{References}

[1] A. Astaneh-Asl, X. Qian, and M. Ozen. (2015, April 21). Push-over Analysis of the Main Tower of the New Self Anchored Suspension Bay Bridge. [Online]. Available: http://www.ozeninc.com/wpcontent/uploads/2015/10/pushover-analysis-of-the-main-tower-of-the-new-self-bay-bridge.pdf

[2] British Standards Institution, "BS5400: Steel, concrete and composite bridges; Part 3: Code of practice for design of steel bridges," 1982.

[3] D. N. Veritas, "Buckling strength analysis of mobile offshore units. Classification Note 30.1," October, 1987.

[4] American Petroleum Institute, "Bulletin on design of flat plate structures. API Bulletin 2V, First Edition," May 1, 1987.

[5] European Convention for Constructional Steelwork, "European recommendations for the design of longitudinally stiffened webs and of stiffened compression flanges. ECCS Technical Working Group 8.3, First Edition,” 1990.

[6] American Association of State Highway Officials (AASHO), "Standard specifications for highway bridges, 9th Ed," Washington, D.C., 1965.

[7] M.R. Horne and R. Narayanan, "An approximate method for the design of stiffened steel compression panels," in Proceedings of Institution of Civil Engineers, 1975, vol. 59, no. 2, pp. 501-14.

[8] G.H. Little, "Stiffened steel compression panels--A theoretical failure analys is," The Structural Engineer, vol. 54. no. 12, pp. 489-500, 1976.

[9] S. Chatterjee and P.J. Dowling, "The design of box girder compression flanges," in Proceedings of International Conference on Steel Plated Structures, ed. P. J. Dowling et al. Imperial College, London, 1977, pp. 196-228.

[10] C. A. Carlsen, "A parametric study of stiffened plates in compression," The Structural Engineer, vol. 58B, no. 2, pp. 33-40, 1980.

[11] T. Usami and H.B. Ge, "Cyclic Behavior of Thin-walled Steel Structures-numerical Analysis," Thin-Walled Structures, vol. 32, pp. 41-80, 1998.

[12] Y. Zheng, T. Usami, and H.B. Ge, "Ductility of Thin-Walled Steel Box Stub-Columns," J. Structural Engineering, vol. 126, no. 11, pp. 1304-311, 2000.

[13] H. Ge, S. Gao, and T. Usami, "Stiffened steel box columns. Part 1: Cyclic behaviour," Earthquake Engineering and Structural Dynamic, vol. 29, pp. 1691-1706, 2000.

[14] C. Yoo, B. Choi, and E. Ford, "Stiffness Requirements for Longitudinally Stiffened Box-Girder Flanges," J. Structural Engineering, vol. 127, no. 6, pp. 705-711, 2001.

[15] American Association of State Highway Transportation Officials (AASHTO), "LRFD Bridge design specifications, 1st Ed," Washington, D.C., 1994

[16] ANSYS, Inc., “ANSYS Mechanical APDL Theory Reference, Release 14.5,” 2012.

[17] American Association of State Highway Transportation Officials (AASHTO), "LRFD Bridge design specifications, 7th Ed," Washington, D.C., 2014. 